\title{
EDITORIAL 22.2 - As publicações científicas e a formação para atuação no campo educativo
}

Este ano de 2018 vem se destacando por diversas ações no campo da Educação as quais a ABRAPEE tem protagonizado ou participado ativamente. Em momentos de crise econômica, social e de direitos, vivenciada pela aprovação de legislações que promovem profundas mudanças na Educação Brasileira, como o congelamento de verbas por 20 anos para a Educação e Saúde, as mudanças curriculares com a redução do conhecimento para crianças e jovens, a aprovação de cursos à distância em praticamente todas as áreas de formação em nível superior, dentre outros, têm produzido ações de resistência, de organização das entidades nacionais, de profissionais das áreas de Ciências Humanas e Sociais frente a tais retrocessos. AABRAPEE vem se mobilizando conjuntamente com a Sociedade Brasileira para o Progresso da Ciência - SBPC, com o Fórum de Entidades Nacionais da Psicologia Brasileira - FENPB, com a União Latino-Americana de Psicologia - ULAPSI, para o enfrentamento ao avanço das políticas neoliberais que, ao promoverem o enxugamento do Estado Brasileiro, trazem consequências perversas à Educação Básica e Superior. Neste ano, representantes da ABRAPEE se fizeram presentes em muitas ações junto aos Fóruns que lutam pela Educação, em audiências públicas sobre a Base Nacional Comum Curricular, sobre o Plano Nacional de Educação e em atividades regionais e nacionais para a revisão das Diretrizes Curriculares Nacionais para os Cursos de Graduação em Psicologia.

Essa resistência se faz presente no ano em que realizamos os Encontros Regionais das Representações da Associação Brasileira de Psicologia Escolar e Educacional, a nossa ABRAPEE. As Representações são espaços de organização de psicólogos escolares em estados brasileiros e permitem que a Associação contemple a diversidade da Psicologia Escolar e Educacional e articule as ações políticas da entidade nacionalmente. Atualmente a ABRAPEE conta com Representações nos Estados de Minas Gerais, Rondônia, Paraná, Goiás, São Paulo e, recentemente, foi criada a Representação no Estado do Piauí. Inaugurando a Representação Piauiense, em agosto tivemos o I Encontro de Psicólogos Escolares Educacionais do Piauí. Em setembro, o IV Encontro Goiano de Psicologia Escolar e Educacional e o VI Encontro Mineiro de Psicologia Escolar e Educacional - EMPEE. No semestre passado, o VII Encontro Paranaense de Psicologia Escolar e Educacional inaugurou o leque de eventos.

2018 também é ano eleitoral. Dentre tantos aspectos caros à qualidade e à dignidade de vida da população, a Educação é ponto crucial! Neste sentido, quais são os projetos educacionais dos candidatos? É uma pergunta que urge ser feita - e respondida. Sabemos que do papel e das palavras às ações concretas, às políticas públicas, pode haver uma grande lacuna, mas a dimensão política do projeto educativo gestado para o país nos revela muito sobre a (des)importância dada a essa seara.

O ano de 2018 também fulgura nos horizontes do Conselho Federal de Psicologia, da Associação Brasileira de Ensino de Psicologia e da Federação Nacional dos Psicólogos que o elegeram como o Ano da Formação do Psicólogo e desencadeou discussões importantes sobre as Diretrizes Curriculares Nacionais para os Cursos de Psicologia de 2004 (Brasil, 2004). Várias reuniões foram chamadas em todo o território nacional e o Relatório até o momento elaborado informa que

As reflexões, apontamentos, indagações aqui presentes representam, ao mesmo tempo, um resgate de elementos históricos, contextuais de nossa formação, uma afirmação de princípios que têm sido orientadores da Psicologia, e um levantamento de questões que possam nortear o processo de revisão das Diretrizes Curriculares Nacionais para os Cursos de Graduação em Psicologia. (Conselho Federal de Psicologia, 2018)1.

Pelo que nos toca como veículo de divulgação científica de parte da produção nacional no campo da Psicologia Escolar e Educacional, as pesquisas e práticas publicadas nestas páginas tanto nos revelam frutos de uma formação quanto inspiram e auxiliam futuros profissionais que se dedicam a trabalhar na área. Da Educação Infantil ao Ensino Superior, perpassando diferentes referenciais teóricos e abordagens em pesquisa, nossa/os leitora/ES têm à disposição um grande elenco de produções que Ihes podem subsidiar tanto em sua formação inicial quanto na continuada. Fica aqui a sugestão de que docentes e supervisora/es de estágio utilizem artigos da Revista como textos para a fundamentação de aulas e discussões teóricas em supervisões.

Se nas décadas passadas lançava-se mão de livros didáticos que, à guisa de cartilhas, orientavam as aulas $^{2}$, há tempos o avanço na produção do conhecimento científico em Psicologia pulverizou-se em artigos, que hoje

1 https://site.cfp.org.br/publicacao/ano-da-formacao-em-psicologia-2018/

2 Eles ainda são usados, mas não como manuais. 
trazem importantes contribuições para o avanço da Psicologia como ciência e profissão e também para a formação profissional. Isso, é claro, não exclui livros e capítulos de livros, mas torna mais acessíveis ao público produções mais recentes, como teses e dissertações. Academia e sociedade, assim, beneficiam-se de diversas pesquisas e práticas desenvolvidas em diferentes âmbitos, contextos, referenciais teóricos e concepções e desenhos metodológicos.

Entretanto, para que esse processo possa continuar provendo pesquisadora/es, estudantes, docentes e a população em geral, é fundamental que também continue havendo auxílio financeiro para a investigação científica assim como para a editoração e publicação de periódicos. Sabemos dos desmantelamentos das universidades públicas e, no bojo das transformações, também são feitos cortes a verbas para a publicação. Urge, portanto, fazer enfrentamentos para que autores possam publicar e divulgar suas pesquisas.

Agradecemos aos pesquisadores e profissionais que têm enviado materiais para a nossa Revista, assim como aos leitores interessados que demonstram a necessidade de fazer investigações na área de Psicologia e áreas afins, criando necessidade de elaborações teóricas para fundamentar a prática. Nesse aspecto, concordamos com Saviani que ao tratar da e relação entre teoria e prática, afirma o seguinte: "quanto mais sólida for a teoria que orienta a prática, tanto mais consistente e eficaz é a atividade prática" (p. 262).

A Psicologia Escolar e Educacional, por meio das pesquisas realizadas, das propostas apresentadas no campo político, fruto das vozes, dos olhares e das reflexões teórico-metodológicas no campo da educação, em seus diversos níveis, se expressa nos artigos aqui apresentados e desafia-nos na compreensão da complexidade do fenômeno educativo e da dimensão educativa da atuação de psicólogas e psicólogos na área de Educação, de Saúde, da Assistência e na Garantia de Direitos.

\section{Referências}

Brasil. Ministério da Educação, Conselho Nacional de Educação/ Câmara de Educação Superior (2004). Parecer 0062/2004, aprovado em 19/02/2004. Diretrizes Curriculares Nacionais para os cursos de graduação em Psicologia. Brasília.

Saviani, D. (2005). Educação socialista, Pedagogia Histórico-Crítica e os desafios da sociedade de classe. In: Lombardi, J. C.; Saviani, D. (orgs.), Marxismo e Educação: debates contemporâneos. (pp. 223-274). Campinas: Autores Associados.

Silvia Maria Cintra da Silva ${ }^{3}$, https://orcid.org/0000-0003-0834-5671

Marilda Gonçalves Dias Facci4, https://orcid.org/0000-0001-7443-490X

Marilene Proença Rebello de Souza5, https://orcid.org/0000-0002-8297-5674

Editoras

3 Universidade Federal de Uberlândia, MG, Brasil.

4 Universidade Estadual de Maringá, Maringá, PR, Brasil.

5 Universidade de São Paulo, São Paulo, Brasil. 